\title{
Project Management Challenges in Implementing Business Intelligence Approach inside Organizations
}

\author{
Dragos Dantis ${ }^{1}$
}

\begin{abstract}
One of the key pillars of organizations for a long time has been to build successful businesses, conquer new markets and overcome turning points in the functioning of their products and services. In practical terms the managers of the companies had to answer to a simple and complex question in the same time, not only towards investors, but as well towards themselves: "How should be managed the company with the available resources in an effective way to arrive to the planned results?" Between the lines this question addresses the path to be adopted by each organization to link the mission with the vision and with the objectives to be met. For many practitioners in the field the answer to the above-mentioned question is rather modest: "the implementation of a business intelligence approach". As we are in the age of knowledge management and the information is characterized by large scale availability, many would say that the answer is quite easy to implement. Nevertheless, professionals with experience would treat with a certain amount of respect this field and would say this has been among the challenges of their career and supported them in understanding better the dynamics of organizations.

Present research paper, links itself to this scenario and would start from the premises that implementing a business intelligence approach constitutes a "must have" for an organization, rather than a "nice to bave". It aims at identifying the challenges behind such projects, trying to deliver at the end some answers to the main tests identified.
\end{abstract}

Keywords: project, business intelligence, stakeholders, strategy, organization.

JEL Classification: $M 00$

DOI: $10.24818 / \mathrm{REJ} / 2021 / 79 / 05$

\section{Introduction}

The context of the research is linked to the desire to structure in specific manner technical information and points identified during the performing of project management initiatives, including implementation and/or testing of business intelligence approaches or applications.

\footnotetext{
${ }^{1}$ Bucharest University of Economic Studies, Bucharest, Romania, dragos.dantis@gmail.com. Year XXIV no. 79

March 2021
} 
Objectives of the research aim in two directions: identification of challenges in project management in the implementation of business intelligence and possible solutions to overcome such challenges.

\section{Problem Statement}

Inside the pages of this research paper will be mentioned aspects identified during the performing of various projects, supporting the argumentation on practical aspects, instead of scientific literature. Value behind the statements enlisted will consider the presentation of various points, some of them with a strategical value, in the understanding of the general background of technological evolution and artificial intelligence. Compared to other fields of activity the business intelligence is an area where the links with previous mentioned factors are direct and inseparable.

\section{Research Questions/Aims of the Research}

The research question will not focus on what it is a project or what is project management. Rather would try to indicate that an organization needs to understand which should be the best methodology to adopt in the implementation of a business intelligence approach.

Nevertheless, as there are several project management methodologies on the market, an organization could direct to any of them for reaching its objectives.

As most of the statements will be based on practical aspects, three factors have been identified in having a clear contribution. Even though, a hierarchical classification cannot be performed as these three factors are linked between them and the success of the implementation depends on the level of flexibility and adaptability of these elements in their relation.

Graphical representation bellow has the role to highlight this statement and should be as clear as possible to the stakeholders of any organization, even in the performing of an initial analysis, in order to identify the path to be chosen. 


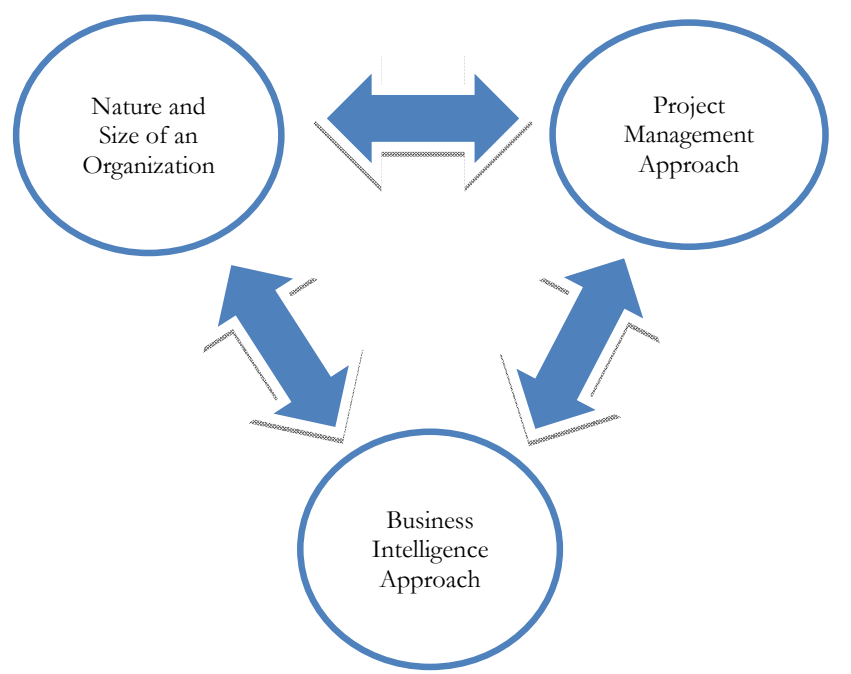

Figure 1. Factors to be considered in B.I. project management Source: author own representation

A clear conceptual illustration of the above schema, allows the stakeholders of any business, to consider the necessary knowledge in the implementation in different areas: integration, scope, time, cost, quality, procurement, human resources, communications, risk management, stakeholder management (www.pmi.org).

\section{Research Methods}

Among the research methods, since many of the ideas behind refer to the strategic level, would be advised for an organization in the beginning of such a project to go for a PESTEL Analysis. Based on the definition provided by (researchmethodology.net) PESTEL (is a strategic analytical tool used to assess external factors affecting businesses. PESTEL acronym stands for political, economic, social, technological, environmental and legal factors impacting companies). Using such a method, the stakeholders of the company would be able to link the strategy, objectives and vision of the legal entity to the project management and to the business intelligence solution.

If the results of such an evaluation are not sufficient or need further elements a next step could be the performing of a SWOT analysis. Based on the experiences in the practical field or testimonials from other professionals, the outcomes behind the implementation of business intelligence approach can be marked by increased effort, numerous challenges, but remarkable benefits. 
One of the conditions mentioned by various teams of specialists is to consider, that, always challenges have to be approached in a mature and flexible manner, to prevent their transformation in vulnerabilities or threats.

In such a case, a deterrent measure would be to connect in this early stage a highlevel risk analysis to identify the risks behind and possible mitigation actions. This assessment will allow even to have a first starting point for future analytical steps. Usually, in this early phase the roundtable of discussions can be quite restricted, being linked to high level profiles and specialists with experience in the implementation of business intelligence projects. A first outcome of the discussions could be the construction of a strategy regarding the implementation, the resources available, the methodology to be used, and the usage or not of external business consultants.

\section{Findings}

There are numerous definitions present on the market regarding the concept of business intelligence.

For IBM the (Business intelligence is an umbrella term for the technology that enables data preparation, data mining, data management, and data visualization. Business intelligence tools and processes allow end users to identify actionable information from raw data, facilitating data-driven decision-making within organizations across various industries). The same source mentions that the (user adoption of BI software continues to increase at a rapid pace, especially as customers migrate workloads to the cloud).

Another interesting definition delivered by (financesonline.com) mentions that (Business intelligence refers to the tools, technologies, applications, and practices that are used to collect, integrate, analyse, and present an organization's raw data to create insightful and actionable business information. BI, as a discipline and as a technology-driven process, is made up of several related activities, including: data mining, online analytical processing, querying, reporting).

Considering above-mentioned definitions and aspects encountered in practice, we have tried to construct a definition for business intelligence approach, in order to have a logical flow with the identified challenges. As a result, we see, the Business Intelligence Approach as a mix of factors at company level: culture, strategy, resources, policies, individual mindset, technical infrastructure, framework to collect, store and analyze the data generated by the activities of an organization.

Year XXIV no. 79

March 2021 
One of the main questions, even serving as motivation for the writing of this article has been to understand how many companies exist in the world in general and how many of them would use a business intelligence approach in particular. For the first question was quite difficult to have an answer. Even though has been of great support the World Bank site, the response being indicated below in graphical representation.

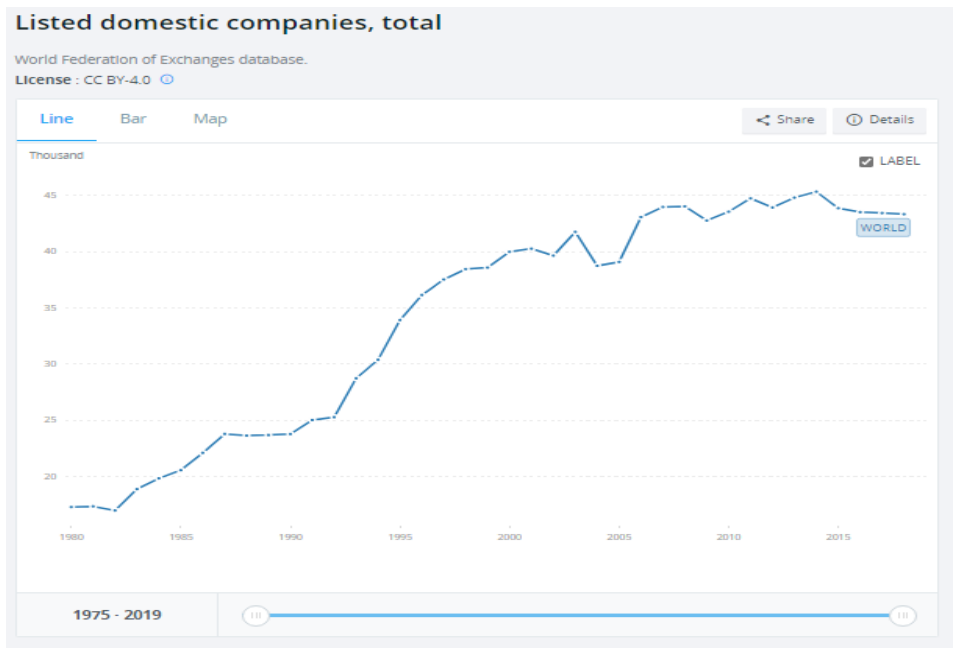

Figure 2. Listed domestic companies, total

Source: www.worldbank.org

For the second question has been even harder to obtain a value behind, as such information represents a strategical competitor advantage and should not be disclosed. Nevertheless, we mentioned the same data, due to the listing of those companies on stock markets, assuming the need of supplementary due diligence and corporate governance measures towards investors and authorities.

\subsection{Project Management Challenges in Implementing BI Approach}

In practice it is considered that the implementation of a BI Approach can be one of the main turning points in the evolution of a company and has to be managed in a proper and flexible manner to reduce the complexity behind and to prevent failure or losses. 
There are many challenges that can impact the launch or the completion of such a project, of which we mention:

- Stakeholder involvement (C1);

- Process owners \& specialists' availability (C2);

- Stakeholders objectives (C3);

- Resources allocated (C4);

- Strategy of development at local/regional/international level (C5);

- Jurisdiction/laws (C6);

- ICT application landscape (C7);

- Granularity of data available and future level needed (C8);

- Data sources (C9);

- Possibility of automation (C10);

- Existence of structured business process methodology (C11);

- Level of existing data collection (C12);

- Necessity to involve externals (C13);

- ICT skills level (C14).

The impact of these factors on the final outcome can be shown as well using a Fishbone or Ishikawa diagram from Lean Six Sigma methodology.

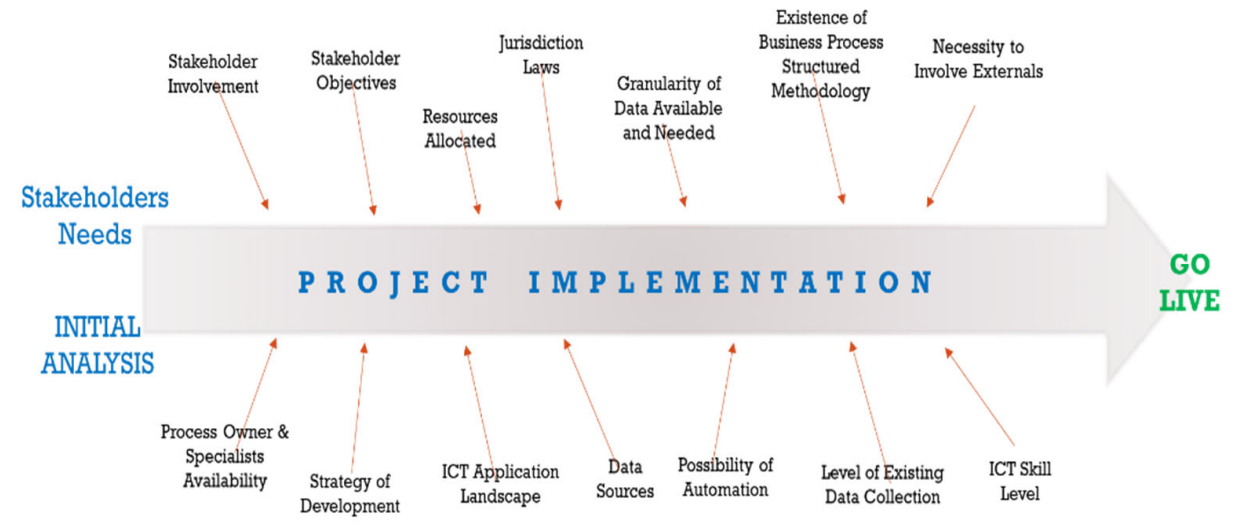

Figure 3. Project management challenges in B.I. approach implementation Source: author own representation 


\subsection{Solutions to Adopt to Mitigate the Challenges}

Based on an internal assessment following solutions have been identified to overcome the challenges encountered in the project implementation, providing additionally a link between the two dimensions:

- The BI Approach and project methodology should be linked to the nature of the organization, to prevent strategical critical delays. It is rather advisable to perform fine tunings during the project, instead of major reworks after the Go Live (S1);

- In case of Holding companies, in-house solutions are easier to identify, using the existing knowledge and best practices (S2);

- Proper communication and change management to motivate the team and indicate issues solved (S3);

- Use of a flexible risk matrix to identify events with probability to impact on the implementation steps (S4);

- Flexibility should be the driving word for each work stream (S5);

- Process Owners and specialists should have a back-up to perform the minimal daily activities to prevent tension, errors or even employee turnover (S6);

- Small PoC can be tested in particular areas during the implementation (S7);

- Reporting status should be done in a balanced manner (S8);

- Allocation or shift of reserve budget (S9);

- Link of benefits cycle with performance indicators values (S10);

- Involvement of external consultants (S11).

Table 1. Connection between challenges (C) and solutions (S) identified

\begin{tabular}{cl}
\hline Challenges (Possible Risks) & Solutions (Mitigation Actions) \\
\hline C1 & S1, S5, S10 \\
C2 & S2, S3, S5, S6, S8, S10 \\
C3 & S10 \\
C4 & S2, S3, S5, S6, S9, S10, S11 \\
C5 & S1, S2, S3, S4, S5, S7, S9 \\
C6 & S2, S4, S11 \\
C7 & S2, S4, S7 \\
C8 & S1, S2, S7 \\
C9 & S1, S2, S7 \\
C10 & S1, S2, S7, S9, S11 \\
C11 & S1, S2 \\
C12 & S1, S2, \\
C13 & S1, S9, S11 \\
C14 & S1, S2, S5, S6, S11 \\
& Source: author own representation
\end{tabular}

Year XXIV no. 79

March 2021 


\section{Conclusions}

The examples presented are founded on author professional experience and may not represent a complete image. Nevertheless, they symbolize a starting point and may be of support for the actors interested in implementing such a project. Value behind arises as well from connecting the possible risks with the mitigation actions, sustaining the initial work of project planning.

This can be enforced by the study of (El-Adaileh \& Foster, 2019) where they have mentioned the need for more research in BI implementation. Furthermore, the same authors mention that existing documentation is based on few cases or literature already published.

What deserves to be highlighted is that at the completion of such a project, the benefits for a company are quite remarkable and justify the effort. Among them can be considered the following:

- Strategic positioning and market competition;

- Better customer understanding and customer satisfaction index increase;

- Data structuring for better analysis and results;

- Benchmarking;

- Better response to requests from investors, auditors, authorities;

- Improved planning and allocation of resources;

- Creation of business continuity scenarios;

- Cost saving;

- Possibility of development;

- Identification of risks, threats, vulnerabilities;

- Supporting of policies and procedures with real information;

- Internal processes redesign;

- Elimination of backlogs;

- Improved productivity;

- Experience from lessons learnt.

Additionally, what has attracted the attention is the statement of (Wieder \& Ossimitzof, 2015), according to whom the proper management of BI is important for data quality and/or information quality, for the diffusion of BI and eventually the benefits of BI. In other words, the starting of such a project is only the beginning of a continuous cycle, where the Business Intelligence Approach is permanently adapted to sustain the development of the organization.

Year XXIV no. 79

March 2021 
Even though the research limitations are inherent to such a theme, the presented information can support further research activity or the launch and planning phase of $\mathrm{BI}$ projects.

In the closing of the paper and to sustain even further some of the idea behind, several quotes of Galileo Galilei are mentioned (https://quotes.thefamouspeople. com/galileo-galilei-123.php):

"The greatest wisdom is to get to know oneself"

"All truths are easy to understand once they are discovered; the point is to discover them".

\section{References}

What Is the Purpose of Business Intelligence in a Business?. Retrieved from https:// financesonline.com/purpose-business-intelligence-business/

El-Adaileh, N.A. \& Foster S. (2019). Successful business intelligence implementation: a systematic literature review. Journal of Work-Applied Management, 2019. Retrieved from https://www.emerald.com/insight/ content/doi/10.1108/JWAM-09-2019-0027/ full/html

Business Intelligence. Retrieved from https://www.ibm.com/analytics/businessintelligence

What is Project Management?. Retrieved from https://www.pmi.org/about/ learn-about-pmi/what-is-project-management

69 Insightful Quotes By Galileo Galilei, The Father Of Science. Retrieved from https://quotes.thefamouspeople.com/galileo-galilei-123.php

PESTEL Analysis, Retrieved from https://research-methodology.net/theory/ strategy/7137-2/

Wieder, B. \& Ossimitz, M.L. The impact of Business Intelligence on the quality of decision-making - a mediation model. Conference on ENTERprise Information Systems / CENTERIS October 2015, p. 1167. Retrieved from https://www.sciencedirect.com/science/article/pii/S1877050915027349

Retrieved from https://www.worldbank.org/ 